\title{
The structure design of underwater riding swimming laps
}

\author{
Zhang Xiaohong ${ }^{1, a^{*}, \text { Wang Jun }}{ }^{2, b}$ \\ ${ }^{1}$ Wuhan Donghu University, China \\ ${ }^{2}$ Hubei University of Technology, China \\ a42777951@qq.com, b1403927584@qq.com
}

\begin{abstract}
Keywords: Swimming laps, Screw, Synchronous belt
Abstract. Recently,the number of swimming pool is increasing, the swimming lover is also rising, more and more people love playing and vacation on the sandy beach. According to statistics, the private swimming pools have tens of thousands in our country, and there are many small swimming pools. Many people love swimming and use it as a way of entertainment and leisure. So the paper design the underwater riding swimming laps, which provide a products of leisure on water, for swimming, fitness, games, fun, and rest, and so on. the characteristics of the product are convenient, novel and energy-saving.
\end{abstract}

\section{Introduction}

Every summer, many children even teenagers want to learn swimming. And teachers will teach them to swim together, include the posture and skills on swimming. But it is dull and boring.

For these people which love to soak in the water and lay on the water on the summer, contact with water for a long time, people will feel very tired, even heat stroke. Every summer there will be many people who is familiar with the water, appear a series of reaction, because of the long time of soaking, even some people are drowned, because of using the improper measures. Some other people caused the accident, because of they are not familiar with the underwater environment, and do not take any measures. However, there are few entertainment products can be used in the water, visitors do not feel pleasure of contacting with water closer.

So our design is the product which is novel, convenient, energy-saving. People can use it for swimming, fitness, games, have fun, and rest and so on.

This paper mainly design the structure of the underwater riding swimming laps through the Solidworks software, and using the 3D model to virtual assembly, kinematics simulation and optimization.

\section{Introduction of the underwater riding swimming laps}

The underwater riding swimming laps is mainly composed of suspension device of swimming laps, pedal power device, synchronous belt transmission device, the propeller propulsion system, people can sit on the water's seat belt, and we can stamped on the pedal to drive the synchronous belt wheel rotating. And driving up the back of the propeller blade propulsion system, to promote the whole swimming laps to go forward. We add a reinforcement link to connect the cycling propulsion on both ends of swimming circle. The pedal power plant including pedals, rocker arm, bearing, seal ring, axis, oil seal, foot pedal drive gear synchronous belt, synchronous belt wheel rotation. It is mainly to solve the difficult to go on and play in the water, swimming beginners is a kind of water can save energy and free entertainment tool.

\section{The choice of scheme}

The propeller propulsion device of the underwater riding swimming laps including by the rear axle, bearing, synchronous belt wheels, propellers, sealed bearing, oil seal, retaining ring, refer to the various kinds of underwater submarine structure, to adapt to various working conditions, and its compact size, the cost is relatively low, due to meet all of the above requirements are often more difficult, so the focus to ensure the propeller propulsion system is an important link in the transmission. Especially in physical model tests, we found that the major problem of difficult to move 
in the water, after discussion and test again and again, finally on the direction of the selection of improved.

1)The suspension device is the swimming laps, in the swimming laps, the rider will sit down on the seat and his foot tread the power device, then through the synchronize pulley will drive the blade to rotate, then it is driven forward, And rider's hands can thrash to change the forward direction. The suspension device reference to the bicycle structure, but it exceeds the bicycle structure, the tightness and cold plastic is better than the bicycle structure, it can work in water without break off. The swimming laps is selected as suspension device, because of its buoyancy is maximum and lots of kids love it. Especially its shape and appearance can be changed with the development needs.

2)The pedal power device is made up of central axis, pedal, pedal of the arm, sealed bearings, oil seal and ring.

\section{The 3D of the underwater riding swimming laps}

The $3 \mathrm{D}$ of the underwater riding swimming laps is FIG.1

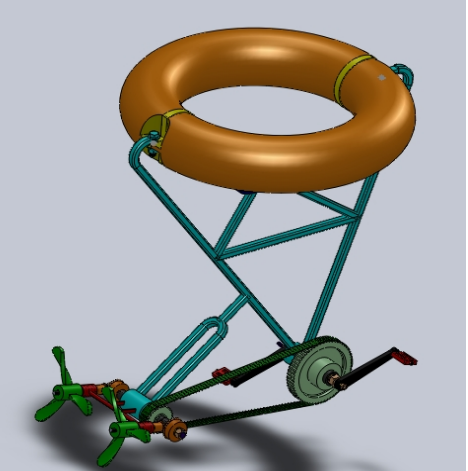

\section{The introduction of parts}

FIG.1 The 3D of the underwater riding swimming laps

1) The pedal power device, which is using pedal power device of the bicycle, only it using synchronous belt wheel to drive, as shown in Fig.2. The two sealed bearing in the middle with shoulder to resist, then the retaining ring and oil seal is used to seal and axially fix, the outside of bearing is connection to sleeve, in order to drive the pedal and radial to rotate ${ }^{[1]}$.

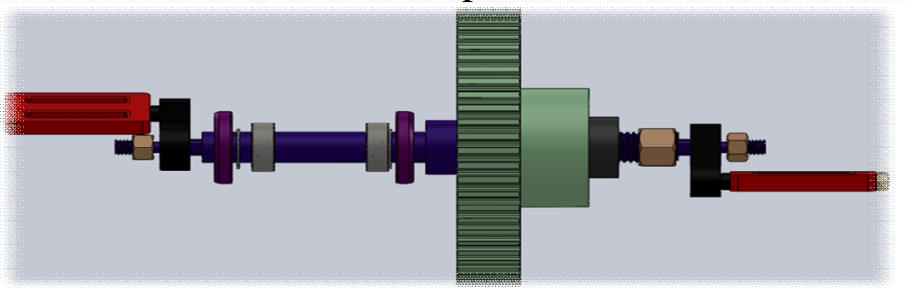

Fig.2 The pedal power device of the underwater riding swimming laps

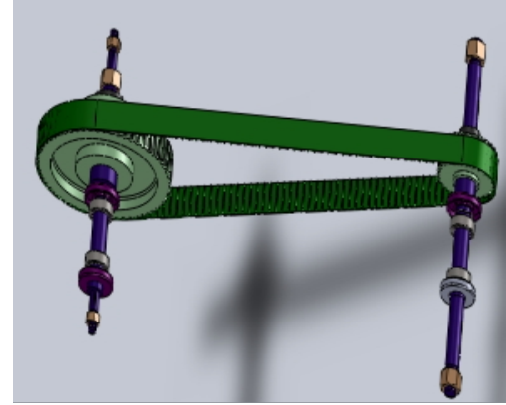

Fig.3 The Transmission device of synchronous belt

(2) Transmission device was chosen synchronous belt wheel ${ }^{[2]}$, as shown in Fig.3, because of the high efficiency and easy to work underwater of synchronous belt wheel, and it has the overload protection function and stability.

(3) The propeller propulsion device as shown in Fig.4, rotation of the front wheels is transmitted to the rear wheels through synchronous belt wheel, The revel gear of rear shaft engages with the turbine blades, thereby driving the turbine blades to rotate. 


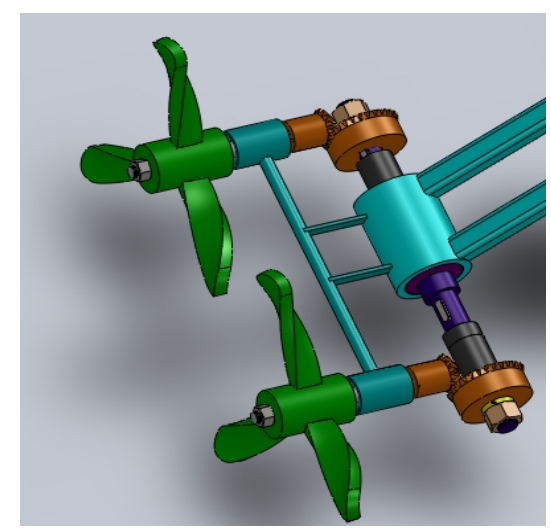

Fig.4 The 3D graph of propeller propulsion device

\section{The important parts of the design parameters}

\section{The design and calculation of synchronous belt}

The transmission ratio of synchronous belt is: $\mathrm{i}=2.4$, the power is: $p \in(10-100) \mathrm{W}$, the central moment is about $500 \mathrm{~mm}$, and next determining the type and size of synchronous belt.

1)Calculating the Design Power of synchronous belt

Calculation formulas and parameters selection:

$$
P_{A}=K_{A} * P=1.3 \times(10 \sim 100)(W)=(13 \sim 1300)(W)=0.013 \sim 1.3(K W)
$$

$\mathrm{P}_{\mathrm{d}^{----------T r a n s f e r ~ p o w e r, ~} \mathrm{KW}}$

$K_{A \text {--------The coefficient of working condition (Lookup table 8-1-74 }}^{[3]}$ )

\section{Determining the type of synchronous belt}

1)Determining circle section system

According to $P_{A}$ and $n_{1}$, the L type of synchronous belt is choosed (Lookup table 8-1-13 $3^{[3]}$ )

$$
P_{b}=9.525
$$

2)Determining the teeth of small pulleys $Z_{1}$

$$
Z_{1}=25 \text { (Lookup table 8-1-60 }{ }^{[3]} \text { ) }
$$

3)Determining the pitch circle diameter of small pulleys $d_{p 1}$

$$
d_{p 1}=\frac{P_{b} Z_{1}}{\pi}=\frac{9.525 \times 25}{\pi} \mathrm{mm}=75.7975 \mathrm{~mm} \approx 75.8 \mathrm{~mm}
$$

4)Determining the teeth of big pulleys $Z_{2}$ (Taking the transmission ratio coefficient $i=2.4$ )

$$
Z_{2}=i \times Z_{1}=2.4 \times 25=60
$$

5) Determining the pitch circle diameter of big pulleys $d_{p 2}$

6) Checking pulley speed $V$

$$
d_{p 2}=\frac{P_{b} Z_{2}}{\pi}=\frac{9.525 \times 60}{\pi} m m=181.9141 \mathrm{~mm} \approx 181.91 \mathrm{~mm}
$$

$$
V=\frac{\pi n_{1} d_{p 1}}{60 \times 1000}=\frac{\pi \times 75.7975 \times 100}{60 \times 1000}=0.3969 \mathrm{~m} / \mathrm{s}<V_{\max }
$$

7) Preliminary determine the center distance $a_{0}$

$$
\text { According to the formula: } 0.7\left(d_{p 1}+d_{p 2}\right) \leq a_{0} \leq 2\left(d_{p 1}+d_{p 2}\right)
$$

$$
180.398 \mathrm{~mm} \leq a_{0} \leq 515.4232 \mathrm{~mm}
$$

8) Determine the pitch line length and the number of teeth $L P_{0}, Z_{\mathrm{b}}$

$$
\begin{aligned}
& L P_{0}=2 \alpha_{o}+\frac{\pi}{2}\left(d_{p 1}+d_{p 2}\right)+\frac{\left(d_{p 2}-d_{p 1}\right)^{2}}{4 \alpha_{0}} \\
& =1404.8124 \mathrm{~mm}
\end{aligned}
$$


Lookup table $8-1-49^{[3]}$, we taking $L_{p}=1422.40 \pm 0.81 \mathrm{~mm}$, code is $560 \mathrm{~L}$, and $\mathrm{Z}_{b}=159$

9) The actual center distance $a$

The center distance can be adjusted : $a \approx a_{0}+\frac{L_{p}-L P_{0}}{2}=508.79 \mathrm{~mm}$

10) Meshing teeth small pulleys $Z_{m}$

$$
Z_{m}=\operatorname{ent}\left[\frac{Z_{1}}{2}-\frac{P_{b} Z_{1}}{2 \pi^{2} a}\left(Z_{2}-Z_{1}\right)\right]=\operatorname{ent}[11.67]=11
$$

11) Basic rated power $P_{0}$

$$
P_{0}=\frac{\left(\mathrm{T}_{a}-m v^{2}\right)}{1000}=0.0968 K W
$$

Basic rated power $P_{0}$ is the rated power of the base width $b_{s 0}$ each synchronous belt $\mathrm{m}$ - Quality of per unit length of pitch width $b_{s 0}$ $T_{a}$ - Allowable working strain of pitch width $b_{s 0}$

The value of $b_{s 0}, T_{a}$, m lookup table 8-1-76 ${ }^{[3]}$

12) Pitch width $b_{s}$

$$
\begin{gathered}
b_{s} \geq b_{S_{O}} \sqrt[1.14]{\frac{P_{d}}{K_{Z} P_{o}}}=23.8279 \mathrm{~mm} \\
b_{s 0}=25.4 \mathrm{~mm}, T_{a}=244 \mathrm{~mm}, \mathrm{~m}=0.095 \mathrm{Kg} / \mathrm{m}
\end{gathered}
$$

The value of $b_{s}$ lookup table $8-1-50^{[3]}$

Trapezoidal synchronous belt:

$$
\begin{aligned}
& b_{s}=25.4_{-1.3}^{+0.5} \mathrm{~mm} \\
& \text { width code is } 100
\end{aligned}
$$

$$
\begin{gathered}
560 \mathrm{~L} 100 \mathrm{~GB} 116616-1989 \\
b_{s}=25.4 \mathrm{~mm}, P_{b}=9.525, L_{p}=1422.4
\end{gathered}
$$

\section{Conclusion}

The product can provide a convenient, novel, energy-saving water play equipment. For swimming, fitness, games, fun, rest, etc. And can be used as the ship's life preserver.To break the fear of water can make swimming beginners, let them experience the fun of in the water, can better familiar with water, learn to swim faster.

\section{Acknowledgment}

This work was financially supported by the science and technology research project of Hubei Provincial Department of Education(B2015300)

\section{References}

[1] Sun Heng, Chen Zuomo, Ge Wenjie, Mechanical principles. Higher education press, Beijing, 2000

[2] Pu Lianggui, Ji Minggang. Mechanical design. [M]. Higher education press,Beijing, 2002

[3] Wu Zongze,Mechanical design handbook[M].Mechanical industry press, Beijing, 2009 